\title{
Democratic Therapeutic Community in a Network of "Enabling Environments": Transformations of Psychotherapeutic Residential Services in Social Postmodern Crisis
}

\author{
Psychologist PhD., Simone Bruschetta \\ Prof., Psychiatrist, Raffaele Barone
}

International Network of Democratic Therapeutic Communities- INDTC, London, UK Email: simonebruschetta@yahoo.it

\author{
Doi:10.5901/ajis.2015.v4n2s2p259
}

\section{Abstract}

The purpose of this article is to present a model for new democratic therapeutic community programmes for seriously ill patients, based on social networks. This model is based on the concept of the Democratic Therapeutic Community in a network of "enabling environments", in a social context of crisis. It represents an evolution of the tradition of Supported Housing as Therapeutic Environment for people with severe and persistent mental illness, in Sicily. A postmodern transition from old Psychiatric Residential Services to new Psychotherapy Community Based. These programmes have given birth to a range of new type of democratic therapeutic community, understood as a new practices of group-psychotherapy community-focused for severe and persistent mental illness. In this article the authors propose and present three type of new DTCs: 1) GroupApartment (GA); 2) Non-Residential Democratic Therapeutic Community (NRDTC); 3) Guest House of Psychotherapeutic Treatment of Crisis (GHPTC). This new model has been developed in Sicily as a response to the serious economic and political crisis of the last decade. It has encouraged mental health professionals to reconsider in the light of the new international interest in mental health 'recovery', the English democratic therapeutic community tradition, and the Italian health care policy choices that with the Law 180/1978, excludes possibility of permanent shelter in psychiatric hospitals, of users with severe mental illness. The Italian health care policy, with the Law 81/2014, definitively closed also the Judiciary Psychiatric Hospitals. So communitarian treatment of these forensic users will be totally in charge of territorial mental health services and of new TCs. Therapeutics processes of this programmes are given by creating 'enabling environments', through psychotherapeutic and psychosocial treatments between the house of users and the place of the therapeutic community, in which 'communal living' is developed as a contexts of care that identify itself as part of a broader social community of purpose and scope, that we use to define the 'Local Community'. The 'therapeutic communal environment' offer suitable care to ameliorate the post-acute phases of mental illness, and play a role of intermediary between the services offered by the NHS and the social community, on one hand, and the caring work carried out by the family as a whole and the job context, on other hand. Three type of new DTCs have been developed from three programmes of "Supported Housing", whit evidences of effectiveness in the scientific field of Mental Health Community-Based: 1) Cooperative Apartment (CA), 2) Supportive Leaving (SL) and 3) Crisis Resolution and Home Treatment Team (CRHTT).

Keywords: Democratic Therapeutic Community, Supported Housing, Recovery in Mental Health, Postmodern Society, GroupAnalysis, Community-Focused Psychoterapy.

\section{Theoretical and clinical references towards a Community-Focused Psychotherapy}

This approach intends to represent also a new practice of group-psychotherapy for serious and persistent mental illness developed by the joining of democratic TC tradition and research (Campling \& Haigh, 2002; Tucker, 1998) within the discipline of Community-Based Mental Health (WHO, 2001, 2005, 2010), according to two programmatic strategies outlined in the Green Paper from the European Commission (European Law - Eur. Com. c. 484 - 14 Oct. 2005, Improving the mental health of the population) to improve the quality of life amongst European citizens, and the social, economic and cultural development as a whole. (1) Improve the consistency of intervention in the health sector as well as between this sector and non-health sectors; first being economic, social, educational, productive, judicial and criminal matters. (2) Promote the participation of a wide range of people, organizations and institutions involved in the search for solutions, the first being patient organizations and the research community.

These new practices are now becoming an integral part of a new Community-Focused Psychotherapy, and can also be seen as a postmodern evolution of democratic TC practice (Barone, Bellia \& Bruschetta, 2010). New DTCs are specific tools developed along this approach concerning a postmodern society in chronic economic crisis such as in 
Sicily. Postmodern society is decentralized post-industrial society, fragmented into a series of micro-social contexts of belonging, which lead to the development of an idea of multi-truth and hyper-reality in relation to knowledge and the world (Lyotard, 1979 ). In postmodern society, social status is wielded by a kind of relational field composed of a multiplicity of "discourses" that stratify certain meanings rather than others (Foucault, 1971).

This new approach and model has been developed in Sicily as a response to the serious economic and political crisis of the last decade. It has encouraged mental health professionals to reconsider the English democratic therapeutic community tradition. This is in light of new international interest in mental health 'recovery' with particular reference to the well-known policy and health law that decreed the closure of asylums in Italy (Italian Law n. 180 - 13 May 1978, Assessments and treatments, voluntary and mandatory) and users direct participation in local mental health services (Italian Law n. 833 - 23 Dec. 1978, Institution of National Health Service).

\section{Transition to New Democratic Therapeutic Communities}

Psychotherapy Community-Focused has developed in Italy the three new programmes, enlarging the bondaries of the concept of DTC, Group-Psychotherapy and Communal Living (Campling \& Haigh, 2002; Tucker, 1998; Barone, Bellia \& Bruschetta, 2010). So, clinical practice developed, refers to a model for Mental Health Community-Based programmes that provide therapeutic support to people with severe mental health problems, to their families and to their carers. It also refers to the active participation in the planning of these Environment of Communal Living, as the fundamental basis not only for designing a therapeutic plan, but also for the development of services for mental health. In order to improve the quality of life of individuals, of families and of services, throw the application of three main scientific references: the value base of Democratic Therapeutic Community (Haigh, 2013), the theory of Social Network (Berkman \& Kawachi, 2000), the social politic of Recovery (Davidson, et al. 2009).

Until now, community care settings to which we refer has been classified under three classic labels of the psychiatric practices (National Collaborating Centre for Mental Health, 2004; American Psychiatric Association, 1997). Each one of these has been developed by the Community-Focused Psychotherapy in Italy (Bruschetta, Barone \& Frasca, 2014).

- The Cooperative Apartment (CA) has been developed in a residence shared by 3-4 patients named GroupApartment (GA), which is not staffed but in which they can accept regular visits by referring professionals. GA is a small residential group of users, based on peer-cooperation and self-help, also about the maintenance of the house and the development of all household activities, in which they receive a specific psychotherapy community-focused.

- The Supportive Leaving (SL) has been developed in Non-Residential Democratic Therapeutic Community (NRDTC), in which the patient shares some of his domestic duties with professionals (who do not live with them) but also with their relatives or their carers (who are well informed, supported and supervised). NRDTC is a group of domestic environments, personal and / or family users property, within which they receive specific home care services that interconnect them to a democratic therapeutic community that meets outdoors.

- The Crisis Resolution and Home Treatment Team (CRHTT) has been developed in Guest House of Psychotherapeutic Treatment of Crisis (GHPTPC), which provide a setting of intensive health support at the patient's home or in a home environment, for the management of acute exacerbations of symptoms, the prevention of re-admission to hospital and at a more rapid improvement of clinical states of a sub-acute phase. GHPTC accommodates users temporarily during symptomatic acute or psychiatric crisis, in which there is a team of professionals who provide health and social treatment alternative to hospitalization.

These new practices are now becoming an integral part of a new Community-Focused Psychotherapy, and can be also seen as a postmodern evolution of the TC practice developed within society in chronic economic crisis.

Community-Focused Psychotherapy is methodologically based on the re-appropriation of personal projects of common life, and stands as the main methodological objective of enabling people with mental illness to deal with others, their own problems, reasoning, thinking and working in conversational way, making it easier to stay together even though uncertainty and undertake together with mutual trust. Clinical practice, this, already anticipated in group analytic meaning in terms of a 'social therapy' (Foulkes, 1975), but also linked to a postmodern social practice better identified with the term 'networking' (Folgheraiter, 2004a, 2004b, 2006).

Community-focused Psychotherapy furnish, in different ways, social support and sanitary coordination, in a more complete, intensive or assertive way, with the purpose of guaranteeing to the users access to the full range of statutory services. This includes primary and specialist medical care, social and legal services, opportunities for education, 
volunteering and employment, assistance with personal and domestic hygiene, and to suitable housing.

\section{Therapeutic Factors of New DTC}

This new approach and model has encouraged mental health professionals to reconsider the English therapeutic community tradition, in the light of the new international interest in mental health 'recovery', and with particular reference to the well-known policy and health law that decreed the closure of asylums (Italian Law n. 180 - 13 May 1978, Assessments and treatments, voluntary and mandatory) and the taking charge of users directly in local mental health services (Italian Law n. 833 - 23 Dec. 1978, Institution of National Health Service).

So, New Democratic Therapeutic Community in Psychotherapy Community-Focused is understood as a type of programme, alternative to hospital or residential communities, which has as its primary objectives to avoid the impact of stigma on patients, and to reduce the costs associated with the protected shelter. The philosophy of this device is based on supporting the development of self-help capability for groups of users, and opening of new collaborative possibilities of every single user with social groups to which it belongs. Creation of a customised home care, group-therapy and peersupported is able to ensure a high quality of life and social inclusion of patients. Main therapeutic factor is the creation of partnerships between users, clinicians, family, mental health services and the other local community stakeholders. Therefore a partnership between the groups of users and staff, and their living environment represented by the social community in which it is included.

Therapeutics processes of this programmes are given by creating 'enabling environments' (Haigh et al., 2014), through psychotherapeutic and psychosocial treatments between the house of users and the place of the therapeutic community, in which 'communal living' is developed as a contexts of care that identify itself as part of a broader social community of purpose and scope, that we use to define the 'Local Community'.

Each New DTC user can receive, according to their clinical and social needs: (1) individual, couple, family and multifamily psychotherapeutic intervention supervised by the psychotherapist groupanalyst; (2) pharmacological treatment carried out by the medical psychiatrist; (3) various types of psychosocial intervention, such as social and practical skills training, house support, employment support and brokerage for services offered by public agencies, supervised by one or two workers; (4) personal support and case management supervised by the personal recovery guide.

The psychotherapist group analyst, medical psychiatrist, psycho-social workers and recovery guides share the same idea of mental illness as being an interpersonal difficulty. The focus of their work is on "relations of power in action" in relation to the social and cultural systems to which they belong (Dalal , 1998). The main therapeutic factor of the New DTC is the analysis of the structural forces, discourses, languages and ideologies, on health and mental illness, just as these forces establish social unconscious (Derrida , 1967; Foulkes, 1975). In compliance with the requirements for postmodern epistemology, ideologies about health and disease are collectively analyzed through a shared and constant reflection on their ability to create violent hierarchies in which one group subjects another, and also of their predisposition to be structured as a language and social structure able to hide the political power differential between the parties involved (Lacan, 1953; Burkitt , 1991).

The New DTC works as a device of psychotherapy community based, when these six therapeutic factors are present. (Barone, Bruschetta \& Bellia, 2010):

1. a theoretical understanding and shared language among clinicians, other staff, users, relatives and purchasers;

2. a practical organisation of the clinical work that gives space to understand the collective narrative of the clinical-social history of the patient, and to the reflection on the relationships among all the involved subjects;

3. a methodology authorised to allow the democratic sharing of decisional power (about specific projects and daily activities) as part of the treatment;

4. to be based on inter-cultural, multi-institutional and multi-modal therapeutic plan, customised for each user, in degree to contemporarily engrave on the family nucleus and on the community context of reference of the users;

5. the clinical intention to build a 'community mental field' that works as a 'group field', to act in a therapeutic sense rather than to cause iatrogenic harm;

6. a treatment programme based on the psychodynamics of the transference between mental fields and of the metallisation of internal states, and a political programme based on the construction of places of personal recovery and social experimentation: both programmes led by an authentic culture of enquiry. 
Therapeutic process can be divided into three types, which correspond roughly to three modes of operation of the group-psychodynamic according to their number of member. The dynamics of small group as supportive living in the House (Living Community - Barone, Bruschetta \& Frasca, 2013). The dynamics of median group as therapeutic communitarian organization (Therapeutic Community - Barone, Bruschetta \& Giunta, 2010). The dynamics of the large group characterized by the local network of services with which user and staff shares a partnership productive, economic, organizational, institutional, civil, cultural and political (Local Community - Barone \& Bruschetta, 2014).

\section{Theoretical and clinical references towards a Recovery-Oriented Psychotherapy}

In this perspective, the practice of pharmacological therapeutics for severe mental disorders, as well as the structure of psychiatric care in the NHS, should be read as an attempt to make natural rules and social structures that are actually the result of specific configurations of power. They can therefore be interpreted as resistance to the change in the configurations of power between the parties involved. This can then trigger iatrogenic processes rather than therapeutic ones, acting in conflict with the achievement of an improved state of well-being based on more new thoughts, feelings and interactions. Even the use of antipsychotic drugs is included in the New DTC with the common awareness of their relative long-term efficacy, as all recovery oriented research has now shown (Hegarty et al., 1994 Harrow, et al., 2012).

In general, however, the personal recovery guides have their hands full focusing on supporting the client's efforts in the present. This forward-looking orientation requires the recovery guide to provide a context for the client's new experiences and learning, but with the full awareness that the recovery processes is guided by the client's preferences, goals, and interests rather than by some imaginary ideal of normalcy held by the provider to which the client is supposed to aspire (Davidson \& Strauss, 1995).

Recovery is not a solitary process, it is fundamentally a social process. Supportive relationships, whether they are with family, friends, professionals, community members, or peers, allow individuals to become interdependent in what we use to define the "Local Community" (Barone, Bellia \& Bruschetta, 2009; 2010; Barone \& Bruschetta, 2014). The role of the recovery guide involves thinking and exploring with the client ways to open doors and enhance access to community involvement while remaining attentive to the ways in which stigma and fear arise and need to be addressed in the process of community (re)integration. To the degree that, at times, this requires broader community education and advocacy becomes an accepted part of the recovery guide's scope of responsibility (Davidson. et al, 2006; 2009).

So, New DTC is understood as a type of treatment that is alternative to hospital or residential communities and whose primary objective is to avoid the impact of stigma on patients and reduce the costs associated with the protected shelter. The philosophy of this device is based on supporting the self-help capability development of the user groups and opening new collaborative possibilities for every single user with the social groups in which they belong to. The creation of customized home care, group therapy and supported housing is able to ensure a high quality of life for the patient and social inclusion. The main therapeutic factor is the creation of partnerships between users, clinicians, family, mental health services and other local community stakeholders. Therefore, a partnership between the New DTC and its living environment represented by the social community in which it is included, especially via the full participation of the users in the local labour market.

The new DTCs for users with SMI are characterized by the strong partnership with the local service network offered by the MHS and by other social organizations, both governative and non-governative, the user's family and the economic context. So, all the new DTCs can be defined as Communal Living Environments of of users in a wider democratic Local Community. Recovery from SMI becomes a fundamental social process based on supportive relationships, and that allows individuals to become interdependents in what we use to define the "Local Community" (Barone \& Bruschetta, 2014). Because, one of the risks of all TC is: "Does it favour social inclusion, or not?"

One of the main therapeutic factors of the New DTCs is the creation of partnerships between users, clinicians, families, mental health services and the other local community stakeholders.

The relationship between the TC and the territory is relevant. "Permeability and impermeability" of the local community depends on the social context, on its resources, formal and informal, public and private, and on the promotional capacity of the empowerment of the users and on the fight against the stigma. The meaning of the therapeutic activities in the TC depends on the support to recovery route, on the autonomy development and on the participation to the democratic life in the local community. In this sense are important the promotional capacities of the local social and working inclusion tools, as for example: IPS-SE (Individual Placement and Support - Supported Employment), Social farms, Social firms "Type B", Vocational Training, Job Bursary and Microcredit Programs (Barone, Bruschetta \& D’Alema, 2013) (Fioritti et al., 2014). 


\section{References}

Barone, R., Bellia, V. and Bruschetta, S. (2009). II sostegno all'abitare come alternativa alla comunità residenziale per la grave patologia mentale. Psicologia di Comunità, 1, 61-74.

Barone, R., Bellia, V. and Bruschetta, S. (2010). Psicoterapia di Comunità. Clinica della partecipazione e politiche di salute mentale. Milano: FrancoAngeli.

Barone, R., Bruschetta, S. and Giunta, S. (2010). Gruppoanalisi e Comunità Terapeutica. Milano: FrancoAngeli.

Barone, R., Bruschetta, S. and D'Alema, M. (2013). L'inclusione sociale e lavorativa in salute mentale. Milano: FrancoAngeli.

Barone, R. and Bruschetta, S. (2014). The therapeutic community in the local community: Social networks between therapeutic community and supported housing. European Journal of Psychotherapy \& Counselling, Volume 16, Issue 1, pp. 69-73.

Barone R., Bruschetta S., Frasca A. (2014), Gruppoanalisi e Sostegno all'Abitare. Domiciliarità e residenzialità nella cura comunitaria della grave patologia mentale. FrancoAngeli, Milano.

Berkman, L. and Kawachi, I. (2000). Social Epydemiology. New York: Oxford University Press.

Bruschetta S., Barone R., Frasca A. (2014), La Ricerca sui Gruppi Comunitari in Salute Mentale. La Valutazione Clinica delle Reti Sociali e la Psicoterapia di Comunità orientata alla Recovery per la Grave Patologia Mentale. FrancoAngeli, Milano.

Burkitt, I. (1991). Social Selves. London: Sage.

Campling P. and Haigh, R. (2002). Therapeutic community research. Past, present and future. London/Philadelphia: Jessica Kingsley Publishers.

Dalal, F. (1998). Taking the Group Seriously. London, Jessica Kingsley.

Davidson, L., and Strauss, J. S. (1995). Beyond the biopsychosocial model: Integrating disorder, health, and recovery. Psychiatry: Interpersonal \& Biological Processes, 58(1), 44-55.

Davidson, L., Tondora, J., Staeheli, M., O'Connell, M.J., Frey, J. and Chinman, M.J. (2006). Recovery Guides: an Emerging Model of Community-Based Care for Adults with Psychiatric Disabilities. In Lightburn, A. and Sessions, P. (Eds.), Community Based Clinical Practice. London: Oxford University Press.

Davidson, L., Tondora, J., Lawless, M.S., O'Connell, M.J. and Rowe, M. (2009). A Practical Guide to Recovery-Oriented Practice: Tools for Transforming Mental Health Care. Oxford University Press, Inc.

Derrida. J. (1967). De la grammatologie. Paris: Les Éditions de Minuit.

Eur. Com. (2005) 484, Green Paper, Improving the mental health of the population: Towards a strategy on mental health for the European Union. Brussels.

Fioritti, A., D'Alema, M., Barone, R., \& Bruschetta, S. (2014). Social enterprises, vocational rehabilitation, supported employment. The Journal of Nervous and Mental Disease, 202, 498-500.

Folgheraiter, F. (2004a). Relational social work. J. Kinsley, London.

Folgheraiter, F. (2004b). Il servizio sociale postmoderno. Erickson, Trento.

Folgheraiter, F. (2006). La cura delle reti. Erickson, Trento.

Foulkes, S.H. (1975). Group-Analytic Psychotherapy. London: Gordon \& Breach.

Foucault, M. (1971). L'ordre du discours. Paris: Gallimard

Haigh R, (2013) The quintessence of a therapeutic environment, Therapeutic Communities: The International Journal of Therapeutic Communities, Vol. 34 Iss: 1, pp. 6 - 15

Haigh, R., Harrison, T., Johnson, R., Paget, S., Williams, S. (2012). "Psychologically informed environments and the "Enabling Environments" initiative", Housing, Care and Support, Vol. 15 Iss: 1, pp.34 - 42

Harrow, M., Jobe TH. and Faull, RN. (2012). Do all schizophrenia patients need antipsychotic treatment continuously throughout their lifetime? A 20-year longitudinal study. Psychol Med, 42(10), 2145-55.

Hegarty, J.D., Baldessarini, R.J., Tohen, M., Waternaux, C. and Oepen, G. (1994 ). One Hundred Years of Schizophrenia: A MetaAnalysis of the Outcome Literature. American Journal Psych., 151 (19), 1409-1416.

Lacan, J. (1953). The function and field of speech and language in psychoanalysis. In The Seminar, Book XX: Encore, On Feminine Sexuality, The Limits of Love and Knowledge 1972-1973

Lyotard, J.F. (1979). La condition postmoderne: rapport sur le savoir. Paris : Les editions de minuit.

National Collaborating Centre for Mental Health (2003). Schizophrenia. Full national clinical guideline on core interventions in primary and secondary care. London: Royal College of Psychiatrists.

Tucker S. (Ed.) (1998). A Therapeutic Community Approach to Care in the Community. London/Philadelphia: Jessica Kingsley Publishers.

World Health Organization (2001). Mental Health: New Understanding. New Hope. Geneva.

World Health Organization (2005). Mental Health Declaration for Europe. Facing the Challenges, Building Solutions. Helsinki.

World Health Organization (2010). User Empowerment in Mental Health. A statement by the WHO Regional Office for Europe. Empowerment is not a destination, but a journey. Copenhagen. 